\title{
Backstepping nonlinear control to maximize energy capture in a variable speed wind turbine
}

\author{
Ouadia EI Maguiri ${ }^{1}$, Driss Moussaif ${ }^{2}$, El alami Smma ${ }^{3}$, Farchi Abdelmajid ${ }^{4}$, Aziz Akhiate ${ }^{5}$ \\ 1,2,3,4IMMII-lab, Faculty of Science and Technology, University Hassan $1^{\text {st }}$, Morocco \\ ${ }^{5}$ RLSEISE-lab, University of Hassan II, ENSAM, Morocco
}

\section{Article Info \\ Article history: \\ Received Mar 1, 2019 \\ Revised Jun 15, 2019 \\ Accepted Jun 27, 2019 \\ Keywords: \\ Backstepping control DC-DC converter \\ DC generator \\ Lyapunov stability \\ MPPT}

\begin{abstract}
We are considering the problem of maximum power point tracking MPPT in wind energy conversion system (WECS). The paper proposes a new control strategy to maximize the wind aerodynamic energy captured in variable speed wind turbine with a separately excited DC-Generator and transformed to the battery through a controlled DC-DC converter. The proposed strategy controls the stip speed ratio via the rotor angular speed to an optimum point at wich the power coefficient is maximal. The controller is designed using the backstepping technique. A formal analysis based on lyapunov stability is developed to describe the control system performances. In addition to closed-loop global asymptotic stability, it is proved that the controller actually meets the MPPT requirement. The above results are confirmed by simulations.
\end{abstract}

Copyright () 2019 Institute of Advanced Engineering and Science. All rights reserved.

\section{Corresponding Author:}

Ouadia El Maguiri,

Department of Electrical and Mechanical Engineering,

Faculty of Science and Technology,

University Hassan $1^{\text {st }}$,

Settat-Morocco.

Email: Ouadia_elmaguiri@yahoo.fr

\section{INTRODUCTION}

In isolated places where no electric grid is available, wind turbines generators (WTG) and photovoltaic (PV) arrays are used to provid electricity. However intermittent characteristic of solar and wind energy creates a need for energy backup. Battery charging is an interesting alternative because of its simplicity and reliability [1-2].

As shown in Figure 1, battery charging application often use a generator that converts wind turbine power to output voltage and a DC-DC converter on its various topologies Buck ,Boost, Buck-Boost [3] and resonant DC/DC converter [4]. Generally the DC generator is a good choice for a (WTG) as it is simply to control and its dynamic characteristics are very good [5]. On another hand, there is a considerable interest in using variable speed wind turbines. Indeed, these can be driven constantly near to the optimum tip-speed ratio $\lambda_{\text {opt }}$ through turbine rotor speed control as shown in Figure 1. Specifically, rotor speed must follow wind-speed variations in low and moderate velocities in order to maximize aerodynamic efficiency. This scheme is known as maximum power point tracking (MPPT) [6].

The Wind generators power production can be mechanically controlled by changing the blade pitch angle [7]. However, (WTG) of special construction are required, which is not the usual case, especially in small-size stand-alone wind energy conversion systems (WECS). 


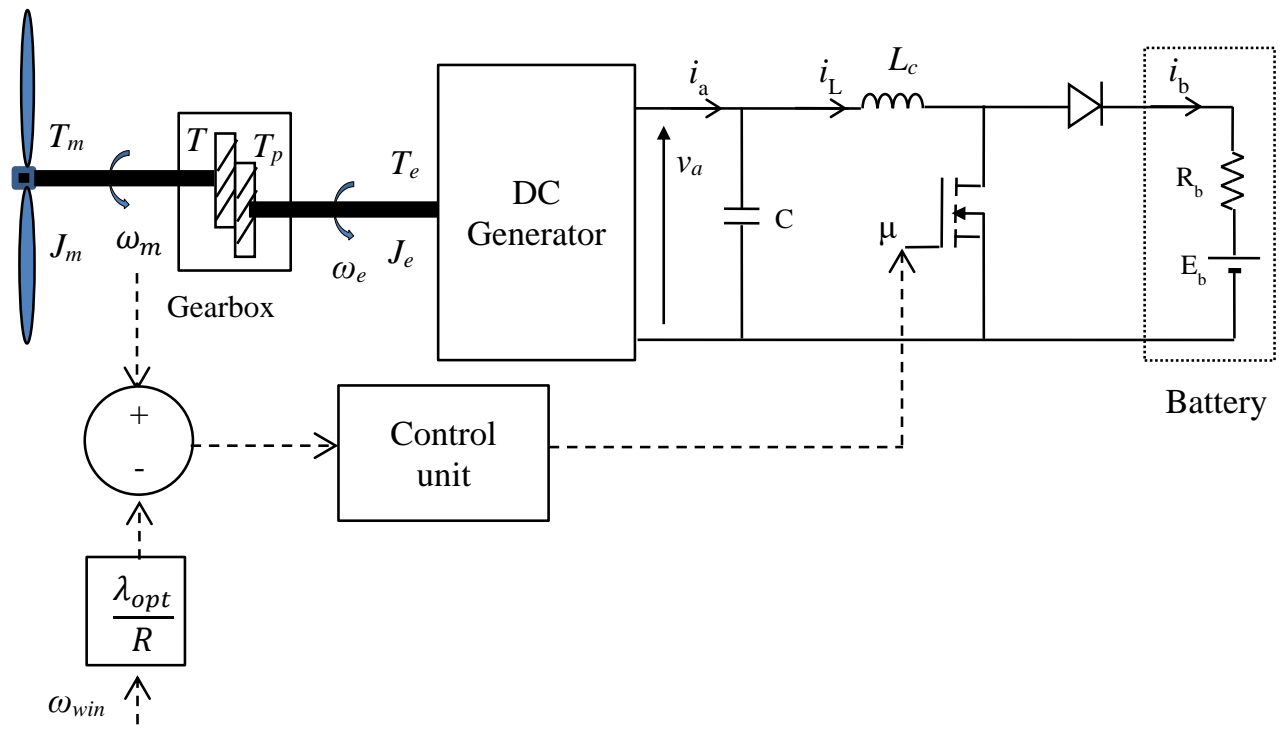

Figure 1. Block diagram of the proposed system

A commonly wind turbine control methods include classical techniques [8-10], which utilize a linearized wind turbine system model. Another common control method is full state feedback [11] which is sensitive to errors in modeling and measurements. In [12], an adaptive sliding mode speed control is proposed. Fuzzy logic control [13] and neural networks [14] have been investigated to reduce the uncertainties faced by classical control methods. In [15] a MPPT algorithm is used for a permanent magnetic synchrone generator using gradient approximation. As the power coefficient $c p$ is difficult to obtain and is different for every turbine, an observer for the estimation of power coefficients in a WECS where a separately excited generator is used in [16].

In this paper, a new control strategy for utilization of WECS in battery charging application is proposed in order to obtain maximum power point tracking (MPPT). A nonlinear controller is developed using the backstepping technique. The controller design is based on a nonlinear model describing the wind turbine, the DC generator, the boost converter, and the battery. It is formally shown that, besides closed loop asymptotic stability, the nonlinear controller actually meets the MPPT requirement. The paper is organized as follows: the controlled system is modelled and given a state space representation in Section 2, the controller designed in Section 3 where its performances are theoretically analysed, the controller performances are further illustrated in Section 4 through numerical simulations, a conclusion and a reference list end the paper.

\section{SYSTEM MODELLING}

The rotor power of the wind turbine $\mathrm{P}_{\mathrm{w}}$ is given by [17-18],

$$
\mathrm{P}_{\mathrm{w}}=\frac{1}{2} \operatorname{cp}(\lambda) \rho \pi \mathrm{R}^{2} \omega_{\text {win }}^{3}
$$

where $\rho$ is the air density, $\mathrm{R}$ is the radius of the swept area of the turbine rotor, $\mathrm{cp}$ is the power coefficient that is function of the tip-speed ratio $\lambda$ for a fixed blade pitch angle, $\omega_{\text {win }}$ is the wind speed. The tip speed ratio is defined as:

$$
\lambda=\frac{\mathrm{R} \omega_{\mathrm{m}}}{\omega_{\mathrm{win}}}
$$

where $\omega_{\mathrm{m}}$ is the wind turbine rotor speed. Figure 2 shows a typical curve of cp versus $\lambda$. For a particular curve it is possible to obtain a polynomial approximation for the $\mathrm{cp}$ as a function of $\lambda$. The maximum value of $c_{p}$, that is $c_{\text {pmax }}=0.407$ is achieved for $\lambda_{\text {opt }}=8.07$. This particular value results in the point of optimal efficiency where the wind turbine captures the maximum power. 


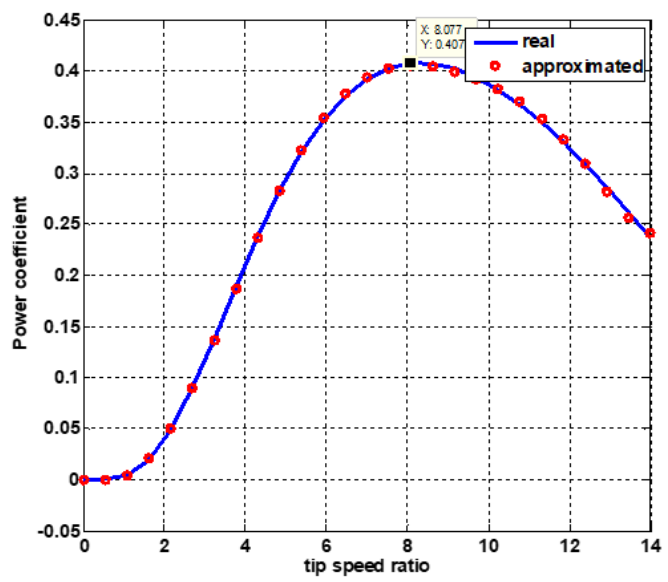

Figure 2. Power coefficient $c p$ versus the tip speed ratio $\lambda$

The polynomial approximation for $c p$ can be expressed as

$$
c p(\lambda)=\sum_{k=0}^{4} \eta_{k} \lambda^{k}
$$

where the coefficients $\eta_{i}$ have a numerical values corresponding to characteristic of used WECS. The order polynomial is taken equal to $n=4$. Since $\lambda$ involves a relation between the rotor speed and the wind speed, it is clear that for a certain wind speed, there is a rotor speed at witch the maximum power point is reached.

The mechanical dynamic of the WECS can be described by the following set of equations [15-16].

$$
\begin{aligned}
& J_{m} \dot{\omega}_{m}+B_{m} \omega_{m}=T_{m}-T \\
& J_{e} \dot{\omega}_{e}+B_{e} \omega_{e}=T_{p}-T_{e} \\
& T_{p} \omega_{e}=T \omega_{m}
\end{aligned}
$$

where $\mathrm{J}_{\mathrm{e}}$ is the total inertia of DC generator, $\mathrm{B}_{\mathrm{e}}$ is the coefficient of viscous friction. $\mathrm{T}_{\mathrm{e}}$ is the electromagnetic torque. $\mathrm{T}_{\mathrm{m}}$ is the rotor torque at the turbine, $\mathrm{J}_{\mathrm{m}}$ is the moment of inertia, $\mathrm{B}_{\mathrm{m}}$ is the frictional constant of turbine and $\omega_{e}$ is the angular velocity of the DC-Geneartor rotor. Note that no torsion related losses are considered here. Furthermore, the transmission is assumed ideal. The transmission gear ratio is defined as

$$
\gamma=\frac{\omega_{e}}{\omega_{m}}
$$

Using (4)-(5) we get the mechanical equation of the WECS:

$$
J \dot{\omega}_{m}+B \omega_{m}=\frac{P_{w}}{\omega_{m}}-\frac{P_{e}}{\omega_{m}}
$$

where

$$
\begin{aligned}
& J=J_{m}+\gamma^{2} J_{e} \\
& B=B_{m}+\gamma^{2} B_{e}
\end{aligned}
$$

In above equations, $J$ denotes the scaled sum of the rotor and generator inertias and $B$ the scaled sum of rotor and generator coefficient of viscous friction. Finally, the WECS model is obtained by combining the dynamics of the DC generator with that of the turbine and is given by:

$$
\begin{aligned}
& \frac{d i_{a}}{d t}=\gamma \frac{k_{e} I_{f} \omega_{m}}{L_{a}}-\frac{R_{a} i_{a}}{L_{a}}-\frac{v_{a}}{L_{a}} \\
& \frac{d \omega_{m}}{d t}=\frac{1}{2} \frac{c p(\lambda) \rho \pi R^{2} \omega_{w i n}^{3}}{J \omega_{m}}-\gamma \frac{k_{e} i_{a}}{J}-\frac{B \omega_{m}}{J}
\end{aligned}
$$

where $\mathrm{L}_{\mathrm{a}}$ and $R_{a}$ are respectively the stator winding inductance and resistance. $k_{e}$ is the induced emf constant, $I_{f}$ the field current and $v_{a}$ armature winding voltage. 
Let us introduce the state variables $x_{1}=\omega_{m}$ and $x_{2}=i_{a}$. Then (8) yields the following state space representation of the combination 'turbine -DC Generator':

$$
\begin{aligned}
\frac{d x_{1}}{d t} & =\frac{1}{2} \frac{c p(\lambda) \rho \pi R^{2} \omega_{w i n}^{3}}{J x_{1}}-\gamma \frac{k_{e} x_{2}}{J}-\frac{B x_{1}}{J} \\
\frac{d x_{2}}{d t} & =\gamma \frac{k_{e} I_{f} x_{1}}{L_{a}}-\frac{R_{a} x_{2}}{L_{a}}-\frac{v_{a}}{L_{a}}
\end{aligned}
$$

Applying well known averaging technique [3-4], one obtains the following average model for the Boost DC-DC converter as shown in Figure 1:

$$
\begin{aligned}
\frac{d x_{3}}{d t} & =-\frac{1}{C} x_{4}+\frac{1}{C} x_{2} \\
\frac{d x_{4}}{d t} & =-(1-\mu) \frac{\left[R_{b} x_{4}+E_{b}\right]}{L}+\frac{1}{L} x_{3}
\end{aligned}
$$

where $x_{3}$ and $x_{4}$ denote respectively the (average) voltage $v_{a}$ and current input $i_{L} ; \mu$ is the average value (over cutting periods) of the binary control. Recall that the continuous signal $\mu$, usually called duty ratio, stands as the control input of the system. The objective is to achieve the MPPT requirement by acting on the duty ratio. The state equations obtained up to now constitute a state- space representation of the whole system including the WECS combined with the DC-DC converter and the battery:

$$
\begin{aligned}
& \dot{x}_{1}=a_{1} c p(\lambda) \lambda^{-1} \omega_{w i n}^{2}-a_{2} x_{1}-a_{3} x_{2} \\
& \dot{x}_{2}=a_{4} x_{1}-a_{5} x_{2}-a_{6} x_{3} \\
& \dot{x}_{3}=-a_{7} x_{4}+a_{7} x_{2} \\
& \dot{x}_{4}=-(1-\mu) \frac{\left[R_{b} x_{4}+E_{b}\right]}{L}+\frac{1}{L} x_{3}
\end{aligned}
$$

where

$$
a_{1}=\frac{\rho \pi R^{3}}{2 J}, a_{2}=\frac{B}{J}, a_{3}=\gamma \frac{k_{e}}{J}, a_{4}=\gamma \frac{k_{e} I_{f}}{L_{a}}, a_{5}=\frac{R_{a}}{L_{a}}, a_{6}=\frac{1}{L_{a}}, a_{7}=\frac{1}{C}
$$

\section{CONTROLLER DESIGN AND STABILITY ANALYSIS}

To facilitate the control developpment process, the following assumptions are considered:

A1) all the system parameters are known and constants.

A2) all states-space $x_{i}(i=1 . .5)$ and the wind speed $\omega_{\text {win }}(t)$ are measurable.

A2) the wind speed $\omega_{\text {win }}(t)$ is constant or slowly time varying (i.e $\dot{\omega}_{\text {win }}(t) \cong 0$ )

The control objective is to enforce the speed $\omega_{m}$ of the wind turbine to track its reference trajectory, $\omega_{m_{\text {ref }}}=R^{-1} \lambda_{\text {opt }} \omega_{\text {win }}$. The maximum power point is reached when $\omega_{m}=\omega_{m_{\text {ref }}}$. Following the backstepping technique [19-21] the controller is designed in four steps:

Step1. let us introduce the speed tracking error:

$$
z_{1}=x_{1}-\omega_{m_{r e f}}^{2}=x_{1}-x_{1}^{*}
$$

In view of (3) and (11) the above error undergoes the (13):

$$
\dot{z}_{1}=a_{1} \sum_{k=0}^{5} \eta_{k} \lambda^{k-1} \omega_{w i n}^{2}-a_{2} x_{1}-a_{3} x_{2}-\dot{x}_{1}^{*}
$$

In (13) the quantity $\alpha=-a_{2} x_{2}$ stands up as a (virtual) control input for the $z_{1}$-dynamics. Let $\alpha^{*}$ denote the stabilizing function (yet to be determined) associated to $\alpha$. It is easily seen from (13) that if $\alpha=\alpha^{*}$ with:

$$
\alpha^{*}=-c_{1} z_{1}-a_{1} \sum_{k=0}^{5} \eta_{k} \lambda^{k-1} \omega_{w i n}^{2}+a_{3} x_{1}+\dot{x}_{1}^{*}
$$

Then one would get $\dot{z}_{1}=-c_{1} z_{1}$ with $c_{1}>0$ is a design parameter. This would clearly ensure asymptotic stability of (13) with respect the Lyapunov function:

$$
V_{1}=0.5 z_{1}^{2}
$$


In effect, the time-derivative of $V_{1}$ would then be:

$$
\dot{V}_{1}=z_{1} \dot{z}_{1}-c_{1} z_{1}^{2}<0
$$

As $\alpha=-a_{2} x_{2}$, is just a virtual control input, one can not set $\alpha=\alpha^{*}$. Nevertheless, the above expression of $\alpha^{*}$ retained as a first stabilization function and a new error is introduced:

$$
z_{2}=\alpha-\alpha^{*}
$$

Using (14)-(17), it follows from (13) that the $z_{1}$-dynamics undergoes the (18):

$$
\dot{z}_{1}=-c_{1} z_{1}+z_{2}
$$

Step 2. The objective now is to enforce the error variable to vanish. $\left(z_{1}, z_{2}\right)$. To this end, let us first determine the dynamics of $z_{2}$ :

$$
\dot{z}_{2}=-a_{2} \dot{x}_{2}-\dot{\alpha}^{*}
$$

Based on the assumption A2; (19) together with (11) and (14) implies:

$$
\dot{z}_{2}=-c_{1} z_{1}-a_{1} \sum_{k=0}^{5}(k-1) \eta_{k} \lambda^{k-2} \dot{\lambda} \omega_{w i n}^{2}+a_{2} x_{1}-a_{2}\left(a_{4} x_{1}-a_{5} x_{2}-a_{6} x_{3}\right)
$$

where in view of $(5)$

$$
\dot{\lambda} \cong \frac{R \dot{x}_{1}}{\omega_{\text {win }}}
$$

The quantity $\alpha_{2}=a_{2} a_{6} x_{3}$ tands as virtual control in (20), let $\alpha_{2}^{*}$ denotes the corresponding stabilizing function associated to $\alpha_{2}$, it is clear that if $\alpha_{2}=\alpha_{2}^{*}$ with:

$$
\alpha_{2}^{*}=-c_{2} z_{2}-z_{1}-a_{1} \sum_{k=0}^{5}(k-1) \eta_{k} \lambda^{(k-2)} \dot{\lambda} \omega_{w i n}^{2}+\left(a_{2} a_{4}-a_{2}\right) x_{1}-a_{2} a_{5} x_{2}
$$

Then one would get $\dot{z}_{2}=-c_{2} z_{2}-z_{1}$ with $c_{2}>0$ is a design parameter. This would clearly ensure asymptotic stability of $\left(z_{1}, z_{2}\right)$ errors with respect the Lyapunov function:

$$
V_{2}=0.5 z_{1}^{2}+0.5 z_{2}^{2}
$$

As $\alpha_{2}=a_{2} a_{6} x_{3}$ is just a virtual control input, one can not set $\alpha_{2}=\alpha_{2}^{*}$. Nevertheless, the above expression of $\alpha_{2}^{*}$ retained as a first stabilization function and the thired error is introduced:

$$
z_{3}=a_{2} a_{6} x_{3}-\alpha_{2}^{*}
$$

Using (22)-(24), it follows from (20) that the $z_{2}$-dynamics undergoes the (25):

$$
\dot{z}_{2}=-c_{2} z_{2}-z_{1}+z_{3}
$$

Step 3. Let us investigate the behavior of the error $z_{3}$, in view of (24), time derivative of $z_{3}$ gives:

$$
\dot{z}_{3}=a_{2} a_{6} \dot{x}_{3}-\dot{\alpha}_{2}^{*}
$$

From $(22)$,it is readily seen that

$$
\begin{aligned}
\dot{\alpha}_{2}^{*}=- & c_{2} \dot{z}_{2}-\dot{z}_{1}+a_{2} a_{4} \dot{x}_{1}-a_{2} a_{5} \dot{x}_{2}-a_{2} \dot{x}_{1}- \\
& a_{1} \sum_{k=0}^{5}(k-1) \eta_{k} \lambda^{(k-2)}\left((k-2) \lambda^{(k-3)} \dot{\lambda}+\ddot{\lambda}\right) \omega_{\text {win }}^{2}
\end{aligned}
$$

Using (11) and (22) it follows from (26) that:

$$
\dot{z}_{3}=a_{2} a_{6}\left(-a_{7} x_{4}+a_{7} x_{2}\right)+c_{2} \dot{z}_{2}+\dot{z}_{1}-\left(a_{2} a_{4}-a_{2}\right) \dot{x}_{1}+a_{2} a_{5} \dot{x}_{2}+a_{1} \sum_{k=0}^{5}(k-1) \eta_{k} \lambda^{(k-2)}
$$




$$
\left((k-2) \lambda^{(k-3)} \dot{\lambda}+\ddot{\lambda}\right) \omega_{\text {win }}^{2}
$$

In (28), the following quantity $\alpha_{3}=-a_{2} a_{6} a_{7} x_{4}$ acts as virtual control. To determine a correspondent stabilizing function $\alpha_{3}^{*}$, let us consider the quadratic augmented Lyapunov function candidate:

$$
V_{3}=0.5 z_{1}^{2}+0.5 z_{2}^{2}+0.5 z_{3}^{2}
$$

Time-derivative of $V_{3}$ along the trajectory of the system $\left(z_{1}, z_{2}, z_{3}\right)$ is given by:

$$
\dot{V}_{3}=-c_{1} z_{1}^{2}-c_{2} z_{2}^{2}+z_{2} z_{3}+z_{3} \dot{z}_{3}
$$

The above expression of $\dot{V}_{3}$ suggest the following stabilizing function

$$
\begin{aligned}
& \alpha_{3}^{*}=-c_{3} z_{3}-a_{2} a_{6} a_{7} x_{2}-c_{2} \dot{z}_{2}-\dot{z}_{1}+\left(a_{2} a_{4}-a_{2}\right) \dot{x}_{1}-a_{2} a_{5} \dot{x}_{2}-z_{2}-a_{1} \sum_{k=0}^{5}(k- \\
& \text { 1) } \eta_{k} \lambda^{(k-2)}\left((k-2) \lambda^{(k-3)} \dot{\lambda}+\ddot{\lambda}\right) \omega_{w i n}^{2}
\end{aligned}
$$

where $c_{3}>0$ is a new parameter design. Let us introduce the following error

$$
z_{4}=\alpha_{3}-\alpha_{3}^{*}
$$

Combining (31) and (32) yields

$$
\dot{z}_{3}=-c_{3} z_{3}-z_{2}+z_{4}
$$

Step 4. The objective now is to enforce the error variables $\left(z_{1}, z_{2}, z_{3}, z_{4}\right)$ to vanish, to this end, let us determine the dynamics of $z_{4}$. Deriving (32) and using (11) one obtains:

$$
\dot{z}_{4}=a_{2} a_{6} a_{7}\left((1-\mu) \frac{\left[R_{b} x_{4}+E_{b}\right]}{L_{c}}+\frac{1}{L_{c}} x_{3}\right)-\dot{\alpha}_{3}^{*}
$$

with

$$
\begin{aligned}
& \dot{\alpha}_{3}^{*}=-c_{3} \dot{z}_{3}-a_{2} a_{6} a_{7} \dot{x}_{2}-c_{2} \ddot{z}_{2}-\ddot{z}_{1}+\left(a_{2} a_{4}-a_{2}\right) \ddot{x}_{1}-a_{2} a_{5} \ddot{x}_{2}-\dot{z}_{2}-a_{1} \sum_{k=0}^{5}(k-1)(k- \\
& \text { 2) } \eta_{k} \lambda^{(k-2)}\left((k-3) \lambda^{(k-4)} \dot{\lambda}^{2}+\lambda^{(k-3)} \ddot{\lambda}+\ddot{\lambda}\right) \omega_{w i n}^{2}-a_{1} \sum_{k=0}^{5}(k-1)(k-2) \eta_{k} \lambda^{(k-3)} \dot{\lambda}((k- \\
& \text { 2) } \left.\lambda^{(k-3)} \dot{\lambda}+\ddot{\lambda}\right) \omega_{\text {win }}^{2}
\end{aligned}
$$

In (35), the actual control input namely $\mu$ arises for the first time; we seek the stabilization of the full error system $\left(z_{1}, z_{2}, z_{3}, z_{4}\right)$ with respect to the following augmented lyapunov function candidate:

$$
V_{4}=V_{3}+0.5 z_{4}^{2}
$$

It is easily checked that, the time derivative of $V_{4}$ is given by:

$$
\dot{V}_{4}=-c_{1} z_{1}^{2}-c_{2} z_{2}^{2}-c_{3} z_{3}^{2}+z_{3} z_{4}+z_{4} \dot{z}_{4}
$$

It is easily checked that the above derivative suggests the following backstepping control law

$$
\mu=1-\left[x_{3}+\left(-c_{4} x_{4}-z_{3}+\dot{\alpha}_{3}^{*}\right) \frac{L_{c}}{a_{2} a_{3} a_{7}}\right] \frac{1}{\left(E_{b}+R_{b} x_{4}\right)}
$$

where $c_{4}>0$ is a new design parameter; that is (37) becomes:

$$
\dot{V}_{4}=-\sum_{k=1}^{4} c_{k} z_{k}^{2}<0
$$


The results obtained up to now are summarized in the following theorem.

Theorem (Main results). Consider the system of fig.1 and described by the model (11) in close loop with the backstepping controller (38); then one has the following properties:

1- all signals are bounded and the tracking errors $\left(z_{1}, z_{2}, z_{3}, z_{4}\right)$ vanish asymptotically

2- the maximization of the energy captured is achieved.

Proof. the $\left(z_{1}, z_{2}, z_{3}, z_{4}\right)$ error-system is given the compact form

$$
\left[\begin{array}{l}
z_{1} \\
z_{2} \\
z_{3} \\
z_{4}
\end{array}\right]=\left[\begin{array}{cccc}
-c_{1} & 1 & 0 & 0 \\
-1 & -c_{2} & 1 & 0 \\
0 & -1 & -c_{3} & 1 \\
0 & 0 & -1 & -c_{4}
\end{array}\right]\left[\begin{array}{l}
z_{1} \\
z_{2} \\
z_{3} \\
z_{4}
\end{array}\right]
$$

it is readily seen from (39) that

$$
\dot{V} \leq-\rho_{1}\left\|\left[z_{1} z_{2} z_{3} z_{4}\right]\right\|^{2}
$$

with

$$
\rho_{1}=\min \left\{c_{1}, c_{2}, c_{3}, c_{4}\right\}
$$

where $\|$.$\| denotes the Euclidian norm, these ensure that the equilibrium \left(z_{1}, z_{2}, z_{3}, z_{4}\right)=(0,0,0,0)$ of the system (11) is globally exponentially stable [20]. The latter ensure the MPPT objective.

\section{PERFORMANCES EVALUATION}

The performances of the proposed control design are illustrated through simulations. The experimental setup, has been simulated in Matlab/Simulink environment. The involved elements have the following characteristics as shown in Table 1:

Table 1. The characteristics of the involved elements

\begin{tabular}{ll}
\hline Battery & $E b=24 \mathrm{~V} ; \mathrm{Rb}=0.65 \Omega$ \\
$D C$ - DC converters & $L_{c}=1 \mathrm{mH} ; \mathrm{C}=4.7 \mathrm{mF} ;$ \\
$D C$ generator & $L_{a}=11 \mathrm{mH} ; R_{a}=1.2 \Omega ; \quad J_{e}=0.208 \mathrm{kgm}^{2}$ \\
Air density & $B e=0.011 \mathrm{kgm}^{2} ; \mathrm{Ke}=0.353 ; I f=0.15 \mathrm{~A}$. \\
Wind turbine & $\rho=1.25$ \\
Transmission gear ratio & $J_{m}=0.1 \mathrm{kgm}^{2} ; B_{m}=0.015 \mathrm{kgm}^{2} ; R=0.5 \mathrm{~m} ; \lambda_{\text {opt }}=6 ;$ \\
\hline
\end{tabular}

The values of $\eta_{k}(k=0 . .4)$ in (3) are:

$\eta_{0}=121 \times 10^{-4} ; \eta_{1}=-302 \times 10^{-4} ; \eta_{2}=196 \times 10^{-4} ; \eta_{3}=-34 \times 10^{-4} ; \eta_{4}=2 \times 10^{-4}$

The controller performances will be evaluated in presence of (time-varying) wind velocity. The wind speed reference as shown in Figure 3 takes a low, medium and high value (equal to 8, 10.7, 14.6 and step to $12.5 \mathrm{~m} / \mathrm{s}$ at times $0,200,400$ and 500 s respectively). With these values of wind speeds, block optimization generates the optimal rotor speed reference shown in Figure 3. The indicated values of design parameters $c_{1}=75 ; c_{2}=20 ; c_{3}=18$ and $c_{4}=15$ have been selected using a try-and-error search method and proved to be suitable. The controller performances are illustrated by Figure 3 and Figure 4; they show that the machine speed perfectly converge to its reference. The tracking quality is quite satisfactory as the response time (after each change in the wind speed) is less than 10s. The perfect MPPT in presence of wind speed changes is shown in Figure 4 . The speed ratio $\lambda$ converges to its optimal value $\lambda_{\text {opt }}=8.07$ for which the power coefficient $C_{p}\left(\lambda_{\text {opt }}\right)=0.407$. 

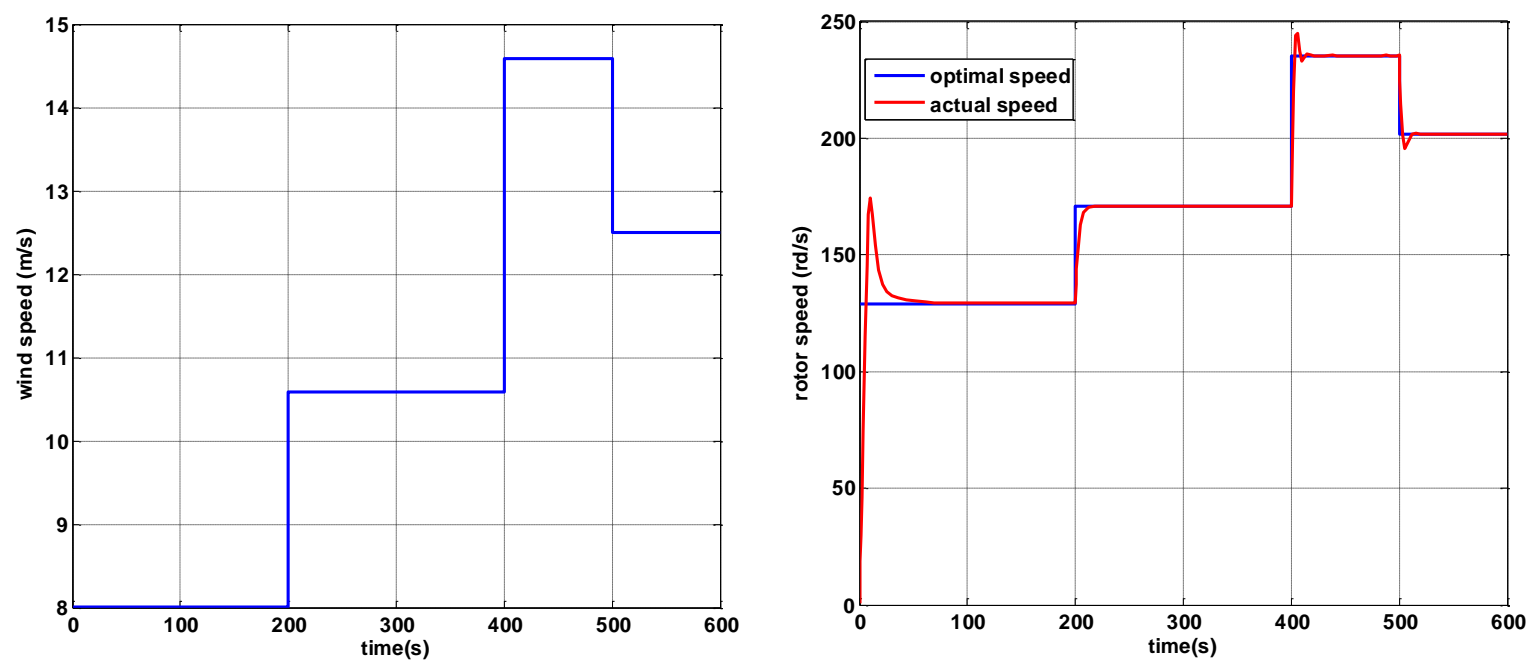

Figure 3. Wind speed and turbine rotor speed profiles
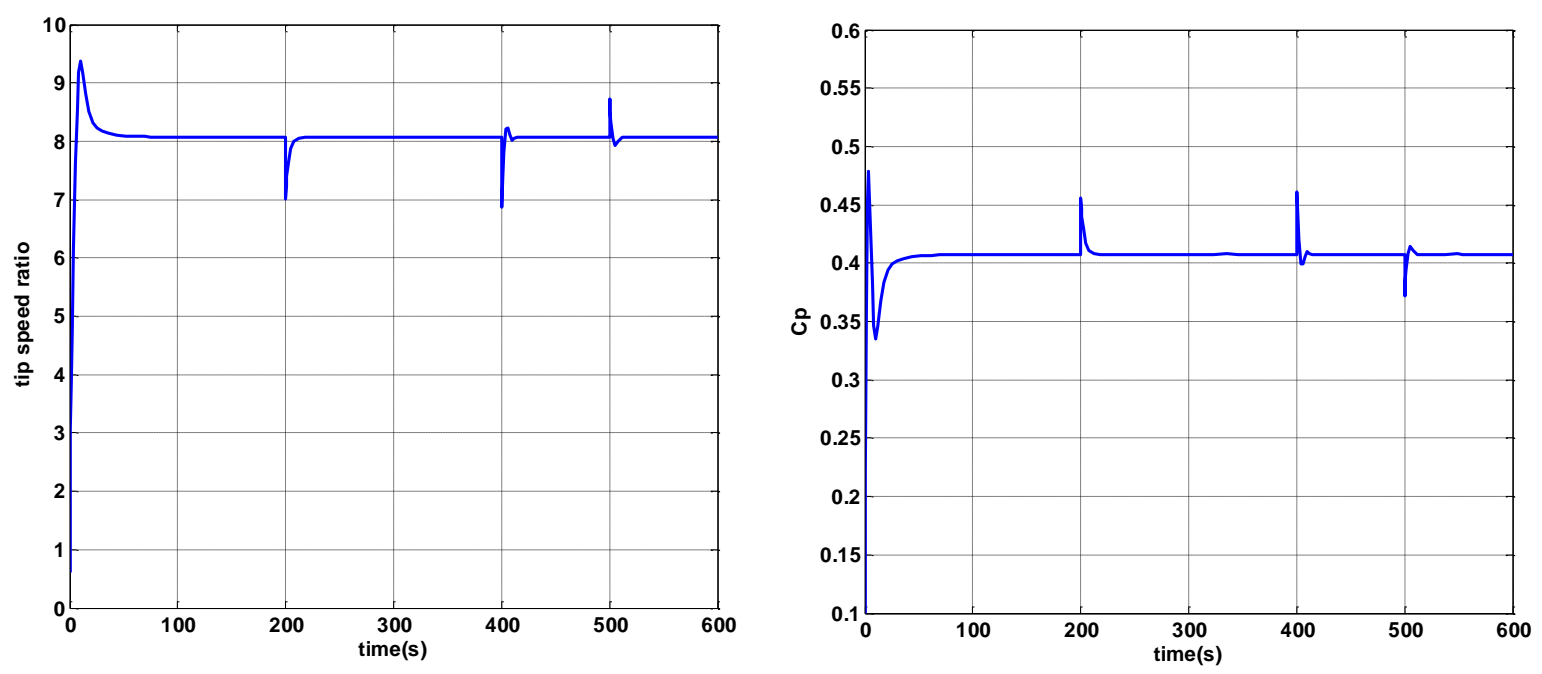

Figure 4. Wind speed ratio $\lambda$ and power coefficient $c p$

\section{CONCLUSION}

In this paper, a new solution to MPPT of variable speed small wind battery-charger system is developed. MPPT is achieved using the nonlinear backstepping controller (38) based on the system nonlinear model (11). The controller is proven to yield a globally uniformly bounded stable closed-loop system via lyapunov-based analysis. Simulation results demonstrate the satisfactory performance of the proposed controller.

\section{REFERENCES}

[1] Z. Chen and F. Blaabjerg, "Wind Energy-The World's Fastest Growing Energy Source," IEEE Power Electronics Society Newsletter, vol. 18, pp. 15-19, 2006.

[2] D. C. Phan and T. H. Trinh, "Maximum Power Extraction Method for Doubly-fed Induction Generator Wind Turbine," International Journal of Electrical and Computer Engineering (IJECE), vol. 8, pp. 711-722, 2018.

[3] H. E. Fadil and F. Giri, "Backstepping Based Control of PWM DC-DC Boost Power Converters," Proceedings of the IEEE ISIE'07, Vigo, Spain, pp. 395-400, 2007.

[4] O. E. Maguiri, et al., "Adaptive control of a class of serie resonant DC-DC converter," IFAC Symposium on Power Plants and Power Systems Control, 2009.

[5] W. Li, et al., "Research on Wind Turbine Emulation based on DC Motor," 2nd IEEE Conf. on Industrial Electronics and Applications, ICIEA 2007, pp. 2589-2593, 2007. 
[6] D. V. N. Ananth and G. V. N. Kumar, "Tip speed ratio based MPPT algorithm and improved field oriented control for extracting optimal real power and independent reactive power control for grid connected doubly fed induction generator," International Journal of Electrical and Computer Engineering, vol. 6, pp.1319-1331, 2016.

[7] F. Lescher, et al., "Robust Gain Scheduling Controller for Pitch Regulated Variable Speed Wind Turbine," Studies in Informatics and Control, vol. 14, pp. 299-315, 2005.

[8] T. Knudsen, et al., "Comparing PI and robust control pitch controllers on a 400KW wind turbine by full scale tests," Department of Control Engineering, Aalborg University, Aalborg, Denmark, Tech. Rep. R-97-4174, 1997.

[9] B. Boukhezzar and H. Siguerdidjane, "Nonlinear Control of Variable-Speed Wind Turbines for Generator Torque Limiting and Power Optimization,” J. Sol. Energy Eng., vol. 128, pp. 516, 2006.

[10] B. Boukhezzar, et al., "Multivariable control strategy for variable speed, variable pitch wind turbines," Renewable Energy, vol. 32, pp. 1273-1287, 2007.

[11] K. Stol and M. Balas, "Full-state feedback control of a variable-speed wind turbine: A comparison of periodic and constant Gains," J. of Solar Energy Eng., vol. 123, pp. 319-326, 2001.

[12] A. Merabet, "Adaptive sliding mode control for wind energy experimental system," Energies, vol. 11, pp. 1-14, 2018.

[13] X. Zhang, et al., "Fuzzy control of variable speed wind turbine," Proc. 6th World Congress on Intelligent Control and Automation, pp. 3872-3876, 2006.

[14] F. Kanellos and N. Hatziargyriou, "A new control scheme for variable speed wind turbine using neural networks," Proc. IEEE Power Eng. Soc. Trans. Distrib. Conf., New York, NY, 2002, pp. 360-365.

[15] S. Morimoto, et al., "Power maximization control of variable-speed wind generation system using permanent magnet synchronous generator," Trans. Inst. Elec. Eng. of Japan, Part B, vol. 123-B, pp. 1573-1579, 2003.

[16] L. D, K. B and M. J., "Estimation of the power coefficient in a wind conversion system," Proceedings of the 44th IEEE Conference on Decision and Control, and the European Control Conference 2005 Seville, Spain, 2005.

[17] I. Munteanu, et al., "Optimal Control of Wind Energy Systems," Springer, 2008.

[18] F. Senani, et al., "A Complete Modeling and Control for Wind Turbine Based of a Doubly Fed Induction Generator using Direct Power Control," International Journal of Power Electronics and Drive Systems (IJPEDS), vol. 8, pp. 1954-1962, 2017.

[19] J. Zhou, et al., "Adaptive backstepping control of Separately Excited DC Motor with Uncertainties," IEE Proc. Elect. Power Appl., vol. 149, pp. 165-172, 2002.

[20] Krstic M., et al., Nonlinear and adaptive control design, John Wilay \& Sons, Inc, 1995.

[21] M. E. Azzaoui, et al., "Backstepping Control of wind and photovoltaic hybrid Renewable Energy System," International Journal of Power Electronics and Drive Systems (IJPEDS), vol. 7, pp. 677-686, 2016. 